\section{Commentary: On-demand computed tomography screening for lung cancer-some surprising results}

\author{
Richard I. Whyte, MD, MBA
}

Lung cancer screening has been shown to reduce lung cancer-related mortality in selected, high-risk populations and, as a result, numerous organizations have established guidelines for the use of this technology. ${ }^{1-4}$ These studies focus on, and recommend, that screening efforts be directed toward certain high-risk demographic groupstypically based on a combination of age and smoking history. Furthermore, the age range typically focuses on the 55- to 80-year age range - the age range recommended by the US Preventive Services Task Force. ${ }^{5}$ The present screening study by Zhang and colleagues, ${ }^{6}$ however, extends the use of screening to a much broader population-to essentially "on-demand" screening.

The ideal screening test should have several characteristics: high sensitivity, high specificity, low risk, and low cost. Furthermore, the utility and cost effectiveness of the test are dependent on the underlying incidence and virulence of the disease in question. For example, for an extremely rare disease of low lethality or morbidity, even a screening test of $100 \%$ sensitivity and specificity may not be cost effective or desirable when resources are limited or other diseases create more pressing public health concerns. Although the technology of computed tomography (CT) scans continues to improve-equal or better resolution with lower radiation doses-the specificity of this technique remains fairly low: in the National Lung Screening Trial, nearly 27,000 individuals had approximately 18,000 "positive" CTs (over 3 years), whereas the total incidence of lung cancers was less than $4 \%$.

From Harvard Medical School and Department of Surgery, Beth Israel Deaconess Medical Center, Boston, Mass.

Disclosures: Author has nothing to disclose with regard to commercial support.

Received for publication Dec 5, 2019; revisions received Dec 5, 2019; accepted for publication Dec 5, 2019; available ahead of print Dec 24, 2019.

Address for reprints: Richard I. Whyte, MD, MBA, Department of Surgery, Beth Israel Deaconess Medical Center, 110 Francis St, Ste 9F, Boston, MA 02215

(E-mail: rwhyte@ bidmc.harvard.edu).

J Thorac Cardiovasc Surg 2020;160:832

$0022-5223 / \$ 36.00$

Copyright (c) 2019 by The American Association for Thoracic Surgery

https://doi.org/10.1016/j.jtcvs.2019.12.027

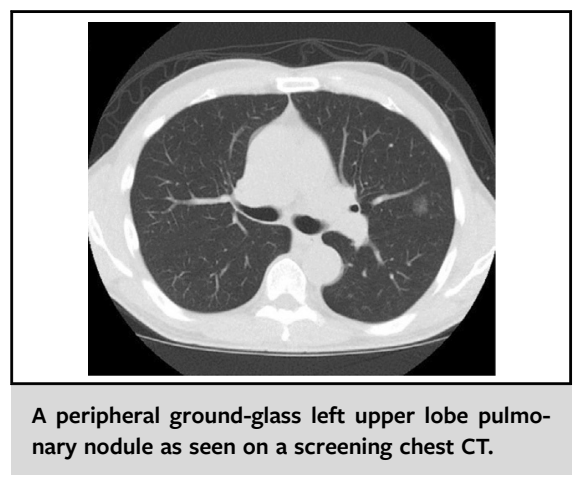

CENTRAL MESSAGE

This lung cancer screening study

of Chinese health care workers

challenges the notion that CT

screening should be reserved for

individuals traditionally felt to be

of "high risk."

One would expect that this high incidence of false positives would only be greater in a relatively unscreened population as one might see in a "screening on-demand" population such as described in this study of unscreened Chinese health care workers. Although the study does not specifically define sensitivity and specificity in the sample population, it demonstrates a surprisingly high, by US standards, rate of lung cancer in a group of presumed-to-behealthy, low-risk health care workers. The rate was, in fact, $2.5 \%$ in women and, even more surprisingly, greater in women than in men and greater in nonsmokers than in smokers-the latter fact being, however, somewhat discounted since this finding did not meet statistical significance.

Why are these findings so different from what we would expect in a US or European study? Is it purely smoking related or are their other influences, such as ambient air quality? Do genetic differences play a role? Certainly, health care workers are not working in conditions classically associated with industrial exposure; however, passive smoke exposure may be playing a greater role than in the United States or Western Europe. The reasons may be due to something entirely different or may be due to a combination of all of the above. In either case, the study challenges the notion that CT screening for lung cancer should only be done in older, long-term smokers. 


\section{References}

1. The National Lung Screening Trial Research Team. Reduced lung-cancer mortality with low-dose computed tomographic screening. N Engl J Med. 2011;365:395-409.

2. Wood DE, Kazerooni EA, Baum SL, Eapen GA, Ettinger DS, Hou L, et al. Lung cancer screening: clinical practice guidelines in oncology. J Natl Compr Canc Netw. 2012;10:240-65.

3. Wender R, Fontham ET, Barrera E Jr, Colditz GA, Church TR, Ettinger DS, et al. American Cancer Society Lung Cancer Screening Guidelines. CA Cancer J Clin. 2013;63:107-17.
4. Kauczor H-U, Bonomo L, Gaga M, Nackaerts K, Peled N, Prokop M, et al ESR/ERS white paper on lung cancer screening. Eur Respir J. 2015;46: 28-39.

5. US Preventive Services Task Force. Lung cancer: screening; . Available at: https:// www.uspreventiveservicestaskforce.org/Page/Document/UpdateSummaryFinal/ lung-cancer-screening. Accessed November 29, 2019.

6. Zhang Y, Jheon S, Li H, Zhang H, Xie Y, Qian B, et al. Results of low-dose computed tomography as a regular health examination among Chinese hospital employees. J Thorac Cardiovasc Surg. 2020;160:824-31.e4.
See Article page 824

\section{Commentary: Pay attention to low-risk populations for lung cancer, but cautiously interpret ground-glass nodules screened by low-dose computed tomography scan}

\author{
Ke-Neng Chen, MD, PhD
}

Traditionally, "high-risk" populations for lung cancer refer to male smokers age 55 to 74 years who have had a malignancy or whose parent(s) had lung cancer. However, due to the widespread application of low-dose computed tomography (LDCT) scanning in China, many young female nonsmokers and those without a history of malignancy or family history have been diagnosed with early-stage lung adenocarcinoma. The nodules manifest as ground-glass nodules (GGNs), which are adenocarcinoma in situ, minimally invasive adenocarcinoma, or lepidic predominant adenocarcinoma pathologically.

Although we are beginning to recognize the authenticity of early-stage lung adenocarcinoma among young females, the phenomenon lacks support from large-sample screening data. Thus, the report by Zhang and colleagues in the Journal ${ }^{1}$

\footnotetext{
From the Thoracic Surgery Department I, Peking University Cancer Hospital, Beijing, China.

Disclosures: Author has nothing to disclose with regard to commercial support.

Received for publication Oct 31, 2019; revisions received Oct 31, 2019; accepted for publication Oct 31, 2019; available ahead of print Nov 27, 2019.

Address for reprints: Ke-Neng Chen, MD, PhD, Thoracic Surgery, Peking University

Cancer Hospital, 52, Fucheng Rd, Haidian District, Beijing, China, 100142

(E-mail: chenkeneng@bjmu.edu.cn).

J Thorac Cardiovasc Surg 2020;160:833-4

$0022-5223 / \$ 36.00$

Copyright (c) 2019 by The American Association for Thoracic Surgery

https://doi.org/10.1016/j.jtcvs.2019.10.204
}

Check for updates

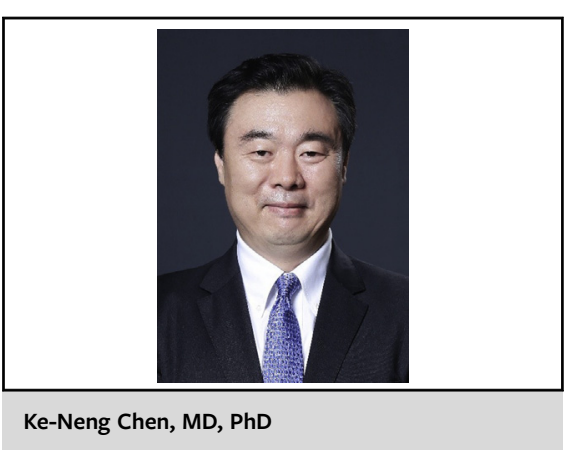

is a major advance. This multicenter, large-sample study included 8392 hospital employees who were screened by LDCT as part of a regular examination. Lung cancer was confirmed in 179 patients $(2.1 \%)$, with detection rates of $2.5 \%$ in females and $1.3 \%$ in males. The incidences in nonsmokers and smokers were $2.2 \%$ and $1.4 \%$, respectively. The detection rates were $1.0 \%$ in patients age $\leq 40$ years, $2.6 \%$ in patients age 40 to 55 years, and $2.9 \%$ in patients age $>55$ years.

With substantial data, Zhang and colleagues document that the high-risk population for lung cancer, at least in China, is undergoing change or has already changed, and that LDCT is identifying more lung cancers among the traditional low-risk populations of nonsmokers and young females. This finding merits attention from government, medical professionals, and society at large. 